\title{
Hangambujeongsan or Kangai Fuzheng Powder shows the anti-cancer effect by enhancing macrophage activation
}

\author{
Wan-Quan Yang ${ }^{1}$, Hyung Soo Han $^{2^{*}, \#}$ \\ 1 : Heqing County Bureau of Public Health, Heqing, Yunnan Province, China, \\ 2 : Department of Physiology, School of Medicine, Kyungpook National University, Daegu, 700-422, South Korea
}

\begin{abstract}
Objectives : Many of currently used anti-cancer drugs were developed to target cell death mechanisms and had serious side effects by causing damage to normal cells. Hangambujeongsan or Kangai Fuzheng Powder was a mixture based on the traditional Chinese medicine. It had been used in the local Chinese hospitals to treat cancer patients for decades and had shown a certain level of beneficial effects without major toxic effects. But its mechanism of action had not been elucidated yet. Thus this study aimed to investigate the effects of Kangai Fuzheng Powder in an in vitro experiment.

Methods : Cancer lines or RAW264.7 mouse macrophage cells were treated with Kangai Fuzheng Powder. Cell viability was measured by MTT assay, and morphological observation was also performed. Gene expression of cytokines in macrophages was determined by real-time polymerase chain reaction. Phagocytic function assay was also performed in macrophage cells.

Results : Kangai Fuzheng Powder had no direct detrimental effect on cancer cells. When macrophages were co-cultured with cancer cells, Kangai Fuzheng Powder had toxic effect on cancer cells. After exposing macrophages to Kangai Fuzheng Powder, macrophages transformed into activated form and the mRNA level of tumor necrosis factor-alpha, interleukin-1beta, interleukin-6, interleukin-10 and monocyte chemotactic protein-1 was significantly enhanced. Phagocytic activity of macrophages was dramatically potentiated.

Conclusions : We demonstrated that anti-cancer effect of Kangai Fuzheng Powder was related to activation of macrophages including enhanced cytokine production and phagocytic function.
\end{abstract}

Key words : Hangambujeongsan or Kangai Fuzheng powder, Macrophage, cytokine, phagocytosis, traditional Chinese medicine

\section{Introduction}

Cancers have been one of the most detrimental diseases to human, and a leading cause of death in many countries. For the last decade, a lot of new anti-cancer drugs has been developed and contributed to the successful treatment of cancer. Some of recently developed drugs have shown specific targets, reducing unnecessary side effects by chemotherapy ${ }^{1-2)}$. However, most of the currently used anti-cancer drugs still have serious side effects such as toxicity to rapidly proliferating normal cells including bone marrow, hair, and gastrointestinal mucosa cells ${ }^{3-6)}$.
Especially, bone marrow suppression could cause immune deficiency and lead to serious infection of the patient $^{7-10)}$. Therefore there have been trials to develop a new type of anti-cancer drugs which have no serious side effects. Some of the traditional Chinese medicines are known to treat cancer by killing cancer cells directly while others are known to enhance the immunity, thereby terminate cancer cells indirectly ${ }^{11-13)}$.

Hangambujeongsan or Kangai Fuzheng Powder is a mixture of many ingredients based on the traditional Chinese medicine remedy used in the clinical treatment of malignant tumors without major toxic or

\footnotetext{
*\#Corresponding author : Hyung Soo Han. Department of Physiology, School of Medicine, Kyungpook National University, Daegu, 700-422, South Korea

· Tel : +82-53-420-4814 · Fax : +82-53-424-3349 · E-mail : hshan@knu.ac.kr

·접수 : 2013년 12월 12일 · 수정 : 2014년 1월 15일 ·채택 : 2014년 1월 15일
} 
side effects ${ }^{14)}$. However, its mechanisms for therapeutic effects has not been investigated yet. Therefore this study aims to investigate the effects of Kangai Fuzheng Powder on cancer cells and macrophages using in vitro culture system.

\section{Materials and Methods}

\section{Reagents and materials}

Kangai Fuzheng Powder is a powder form of medicine made of mixture of many traditional Chinese traditional medicinal ingredients such as Zhi Ke (Citrus aurantium L.), Zang Hong Hua (Crocus sativus), Yún Nán Zhòng Lóu (Rhizoma Paridis Yunnanensis), Quán Xiē (Scorpion), She Tui (Elaphe carinata), Jia Yu (Trionychidae), Ganqi (Resina toxicodendri). Kangai Fuzheng Powder is developed by Mr. Yang WanQuan and his private pharmaceutical facility at Heqing County (Yunnan Province, China) is in charge of the production and supply of this drug. $10 \mathrm{~g}$ of powder was mixed with $100 \mathrm{ml}$ of culture media used for the cell culture study in this experiment and sonicated for 10 minutes on ice. The suspension was filtered with $0.22 \mu \mathrm{m}$ membrane filter from Millipore (Darmstadt, Germany) to remove debris and endotoxin. Filtered solution was isolated and kept in $-70^{\circ} \mathrm{C}$ as a stock solution $(100 \mathrm{mg} / \mathrm{ml})$. The stock solution was thawed and diluted with culture media before use. The final concentrations of Kangai Fuzheng Powder in the culture media were $0.01,0.1,1,10,100,1,000$ and $10,000 \mu \mathrm{g} / \mathrm{ml}$. Other chemical reagents were obtained from Sigma Chemical Co. (St Louis, MO, USA) and culture media and supplements were from Invitrogen (Carlsbad, CA, USA) and HyClone (South Logan, UT, USA).

\section{Cell Culture and treatment}

RAW264.7 (mouse macrophage), BV2 (mouse microglia), A549 (human lung cancer cell), Dul45 (human prostatic cancer cell), Hep3B (human hepatic cancer cell), SK-BR-3 (human breast cancer cell), MCF7 (human breast cancer cell) and SNU354 (human hepatic cancer cell) cell lines were used in this experiment. Cells were cultured in culture media as suggested by provider' $\mathrm{s}$ manual. The cells were incubated at $37^{\circ} \mathrm{C}$ under a humidified atmosphere of 95\% air and $5 \% \mathrm{CO}_{2}$. To observe the indirect effect of Kangai Fuzheng Powder we co-cultured macrophages on the membrane of Transwell insert (Corning, USA) and cancer cells on the bottom of the same plate well while direct effect was measured by applying Kangai Fuzheng Powder to the cells in the regular culture plate. Lipopolysaccharide (LPS, $1 \mu \mathrm{g} / \mathrm{ml}$ ) was used as the activator of macrophages and LPS treated macrophage sample was used as a positive control. Morphological changes were observed under inverted microscope (Olympus IX51, Japan).

\section{Cell viability assay}

Cells were seeded in $24-$ well culture plates $\left(4 \times 10^{4}\right.$ cells/well) and incubated at $37^{\circ} \mathrm{C}$ in complete media for $16 \mathrm{~h}$ before the drug treatment. Kangai Fuzheng Powder was treated into the culture media for 48 hours and cellular injury was observed morphologically using microscope (Olympus IX51, Japan) and biochemically using 3-(4, 5-dimethylthiazol-2-yl)-2, 5-diphenyltetrazolium bromide (MTT) assay. MTT assay was done as previously described ${ }^{15)}$. Briefly, MTT was added to each well, and the cells were incubated for $4 \mathrm{~h}$ at $37^{\circ} \mathrm{C}$. After discarding the culture media, dimethyl sulfoxide (DMSO) was added to dissolve the formazan dye. Absorbance at $570 \mathrm{~nm}$ was measured with the GENius Plus microplate reader (Tecan, Männedorf, Switzerland).

\section{Real-time polymerase chain reaction (PCR) analysis}

Total RNA was isolated from cultured cells using RNeasy Mini Kit (Qiagen, USA). Aliquots of total ribonucleic acid (RNA) were reverse transcribed into single-stranded complementary deoxyribonucleic acid (cDNA) by High-Capacity cDNA Reverse Transcription Kits (Applied Biosystems, Foster City, CA). Sequence-specific primers for the SYBR Green assay were designed with Primer Express 1.0 software (Applied Biosystems, Foster City, CA). Real-time PCR was done in triplicate on a 7500 Real time PCR system (Applied Biosystems, Foster City, CA). Relative gene expression was analysed with the comparative $\mathrm{Ct}$ method with glyceraldehyde 3-phosphate dehydrogenase (GAPDH) as the endogenous control after confirming that the efficiencies of the target and the endogenous control amplifications were approximately equal. Results are presented as target gene expression normalized to GAPDH. The kit contains HotStarTaq polymerase which is included to avoid false positives in the quantitative PCR. Nucleotide sequences of the primers were displayed in Table 1. 
Table 1 : Primers for Real-time PCR

\begin{tabular}{ll}
\hline \multicolumn{1}{c}{ Gene name } & \multicolumn{1}{c}{ Sequence $\left(\begin{array}{l}5^{\prime} \\
\hline \hline \text { TNF-alpha } \mathrm{F}\end{array} 3^{\prime}\right)$} \\
TNF-alpha R & GAT CTC AAA GAC AAC CAA CAT GTG \\
IL-1beta F & CTC CAG CTG GAA GAC TCC TCC CAG \\
IL-1beta R & CCA GGA TGA GGA CAT GAG CAC C \\
IL-6 F & TTC TCT GCA GAC TCA AAC TCC AC \\
IL-6 R & ACT TCC ATC CAG TTG CCT TC \\
IL-10 F & TTC TCA TTT CCA CGA TTT CC \\
IL-10 R & AGT GGA GCA GGT GAA GAG TG \\
MCP-1 F & TTC GGA GAG AGG TAC AAA CG \\
MCP-1 R & CCC ACT CAC CTG CTG CTA CT \\
GAPDH F & TCT GGA CCC ATT CCT TCT TG \\
GAPDH R & GCC AAG GTC ATC CAT GAC AAC \\
\hline & AGT GTA GCC CAA GAT GCC CTT \\
\hline
\end{tabular}

\section{Phagocytosis assay}

Phagocytosis assay kit (Molecular probes, V6694; FITC-E.Coli, USA) was purchased and all the experiments were done according to the vender' s manual. Briefly, $2 \mathrm{~h}$ after adding fluorescein isothiocyanate (FITC) labeled bacterial cell debris into the cultured macrophage, observation of the phagocytosis of bacterial cell debris by macrophage was done with inverted microscope (Olympus IX51, Japan) and measurement of FITC fluorescence signal using the GENius Plus microplate reader (Tecan, Männedorf, Switzerland) was performed.

\section{Statistical analysis}

Data were represented as the mean $\pm \mathrm{SE}$. Comparisons between groups were performed using ProStat software (Poly Software International, Inc, USA). Significant difference was considered at $\mathrm{p}<0.05$ using one-way analysis of variance (ANOVA) followed by Tukey' $s$ multiple comparison procedure.

\section{Results}

\section{Cellular toxicity}

Kangai Fuzheng Powder showed no direct toxicity to cancer cells at the dosages lower than $1 \mathrm{mg} / \mathrm{ml}$ and $10 \mathrm{mg} / \mathrm{ml}$ was the only concentration demonstrating direct toxicity (Fig. 1). At the lower concentration (1 and $10 \mu \mathrm{g} / \mathrm{ml}$ ), some cancer cells even showed proliferating tendency. $10 \mathrm{mg} / \mathrm{ml}$ is a very high therapeutic dosage compared to the usual range of other anti-cancer drugs and should be over the clinically used dosage range of Kangai Fuzheng Powder since patients are prescribed to take 2-3 grams three times per day orally. Immune cells such as macrophages and microglia showed a little different pattern. Kangai Fuzheng Powder caused direct toxicity to these cells even at lower concentrations. Macrophages were more susceptible to Kangai Fuzheng Powder than microglia (Fig. 2).
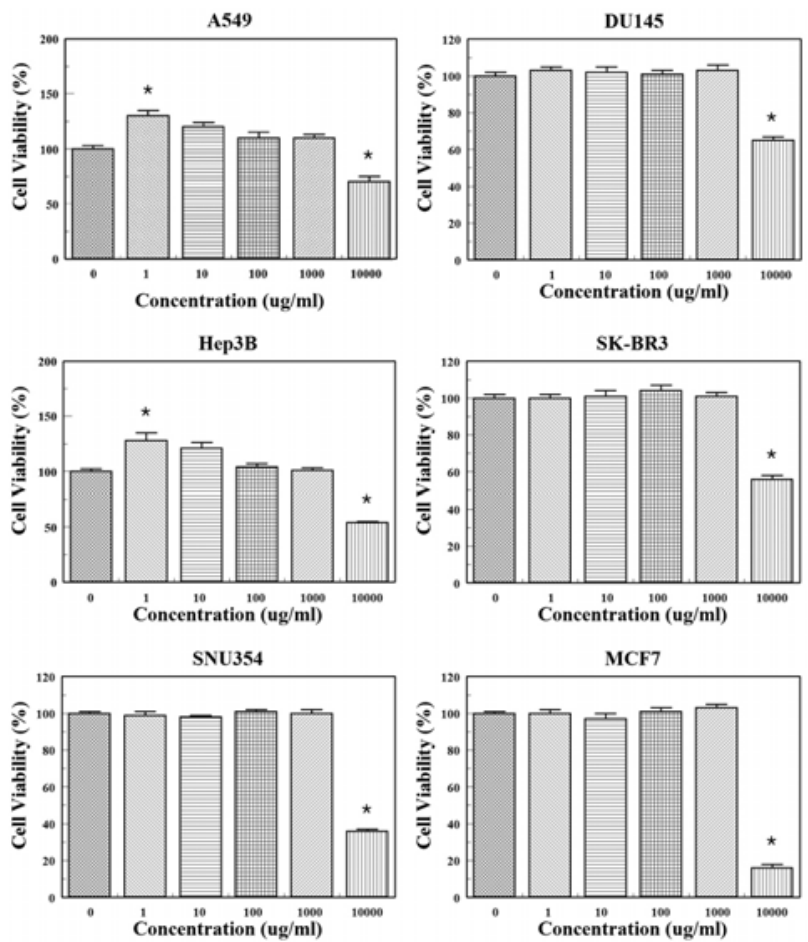

Fig. 1. Cytotoxicity assay in cancer cells after Kangai Fuzheng Powder treatment. Cytotoxic effect of Kangai Fuzheng Powder was measured with MTT assay. All the cancer cells tested in this experiment including A549, Dul45, Hep3B, SK-BR-3, MCF7 and SNU354, showed no damage at concentrations up to $1 \mathrm{mg} / \mathrm{ml}$. Cellular toxicity was obvious only at very high concentration (10 $\mathrm{mg} / \mathrm{ml}$ ) after $48 \mathrm{~h}$ of drug treatment. Statistically significant at $\mathrm{P}<$ 0.05 of values ${ }^{*}$ compared with the concentration at 0 .
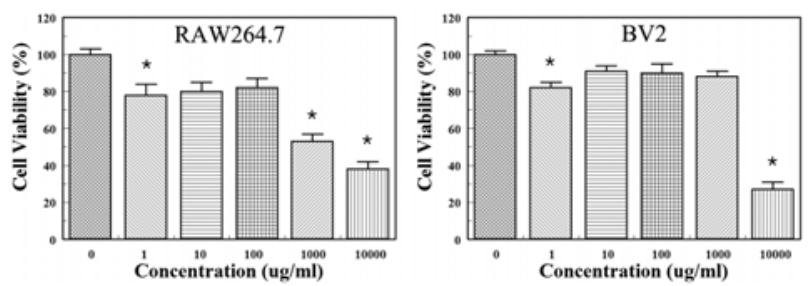

Fig. 2. Cytotoxicity assay in immune cells after Kangai Fuzheng Powder treatment. Cytotoxic effect of Kangai Fuzheng Powder was measured with MTT assay. Immune cells, RAW264.7 macrophages and BV2 microglia, showed direct damage by drug treatment at lower doses. Statistically significant at $\mathrm{P}<0.05$ of values * compared with the concentration at 0 .

We expect that this direct injury should be mediated by macrophages themselves and macrophage mediated toxicity might be related with anti-cancer effect shown in clinical cases. To investigate the macrophage mediated toxicity, we observed indirect effect of Kangai Fuzheng Powder in the cancer cell and macrophage co-culture system. By plating MCF7 cancer cells in the bottom of culture plate and seeding the macrophages on the membrane of Transwell insert, two cells are placed in the same culture media with some distance. MCF7 cells showed no direct toxicity to Kangai Fuzheng Powder at the dosages below 1 $\mathrm{mg} / \mathrm{ml}$ but demonstrated indirect toxicity even at 1 $\mu \mathrm{g} / \mathrm{ml}$. Indirect toxicity was increased dose dependently 
(Fig. 3). This data indicate that some biologically active materials secreted from the macrophages caused toxicity to cancer cells. To further investigate the precise reason of indirect toxicity we performed more experiments.
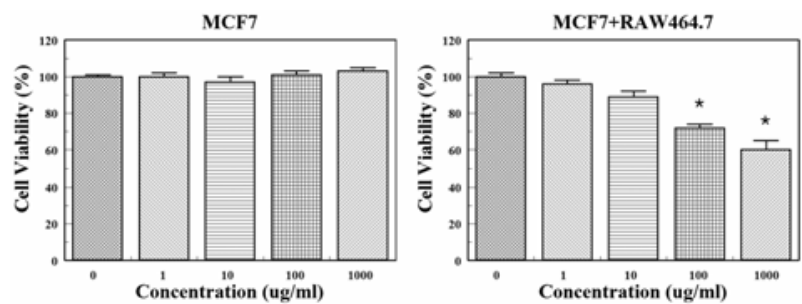

Fig. 3. Cytotoxicity assay in co-culture system after Kangai Fuzheng Powder treatment. Cytotoxic effect of Kangai Fuzheng Powder was measured with MTT assay. MCF7 cancer cells co-cultured with RAW264.7 macrophages showed damage after drug treatment while there was no toxicity in MCF7 cells without macrophages. Statistically significant at $\mathrm{P}<0.05$ of values * compared with the concentration at 0 .

\section{Morphological changes of macrophage}

When macrophages were treated with Kangai Fuzheng Powder, there were dramatic morphological changes in macrophages. Normal resting macrophages were small and round shaped cells. When cells were exposed to lipopolysaccharide (LPS, $1 \mathrm{\mu g} / \mathrm{ml}$ ), they transformed into larger activated cells as it is well demonstrated by other previous studies. At lower doses (1 and 10 $\mu \mathrm{g} / \mathrm{ml})$, Kangai Fuzheng Powder activated cells are minimal and macrophages became bigger cells with multiple podia on the surface at higher doses (100 and $1000 \mu \mathrm{g} / \mathrm{ml}$ ). When macrophages were activated, the number of cells observed under the microscope was less than non-activated cells (Fig. 4). This morphological transformation implies Kangai Fuzheng Powder can stimulate macrophages. Activation of macrophages was further confirmed by measuring cytokine induction and phagocytosis activity in the next step.
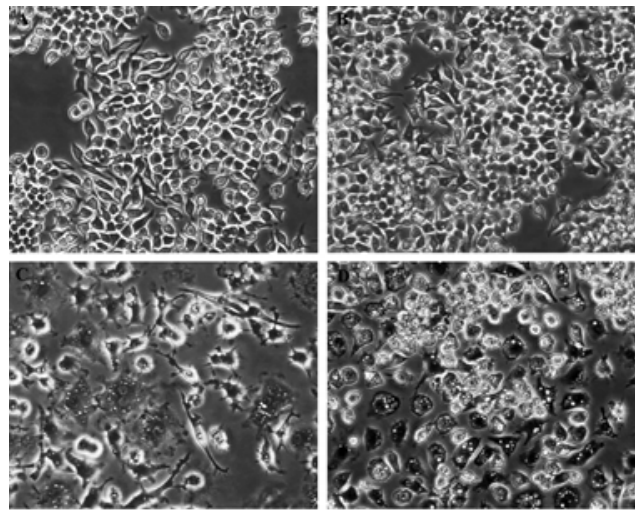

Fig. 4. Morphological changes under microscope. Morphological features of Raw264.7 macrophage cells under normal culture condition (A), after activation by LPS $(1 \mathrm{\mu g} / \mathrm{ml})(B)$, and $10 \mu \mathrm{g} / \mathrm{ml}$ (C) or $1000 \mathrm{mg} / \mathrm{ml}$ (D) of Kangai Fuzheng Powder treatment.

\section{Cytokine gene expression of macrophage}

Kangai Fuzheng Powder was administered to macrophages and RNA sampling was done at 1, 24 and $48 \mathrm{~h}$ after drug treatment and induction of cytokines was observed. From Kangai Fuzheng Powder treated macrophages total RNA was isolated and reverse transcription was performed to obtain cDNA. Using these cDNAs we performed real-time PCR analysis of some representative cytokines. Induction of tumor necrosis factor (TNF)-alpha and interleukin (IL)-1beta was marked at $1 \mathrm{~h}$ while IL-6, IL-10 and monocyte chemotactic protein (MCP)-1 were prominently induced at 24 and $48 \mathrm{~h}$. This induction of cytokines was dose-dependently increased with highest level at $1000 \mu \mathrm{g} / \mathrm{ml}$ (Fig. 5). The time profiles of cytokines induction by Kangai Fuzheng Powder was similar to LPS mediated induction.
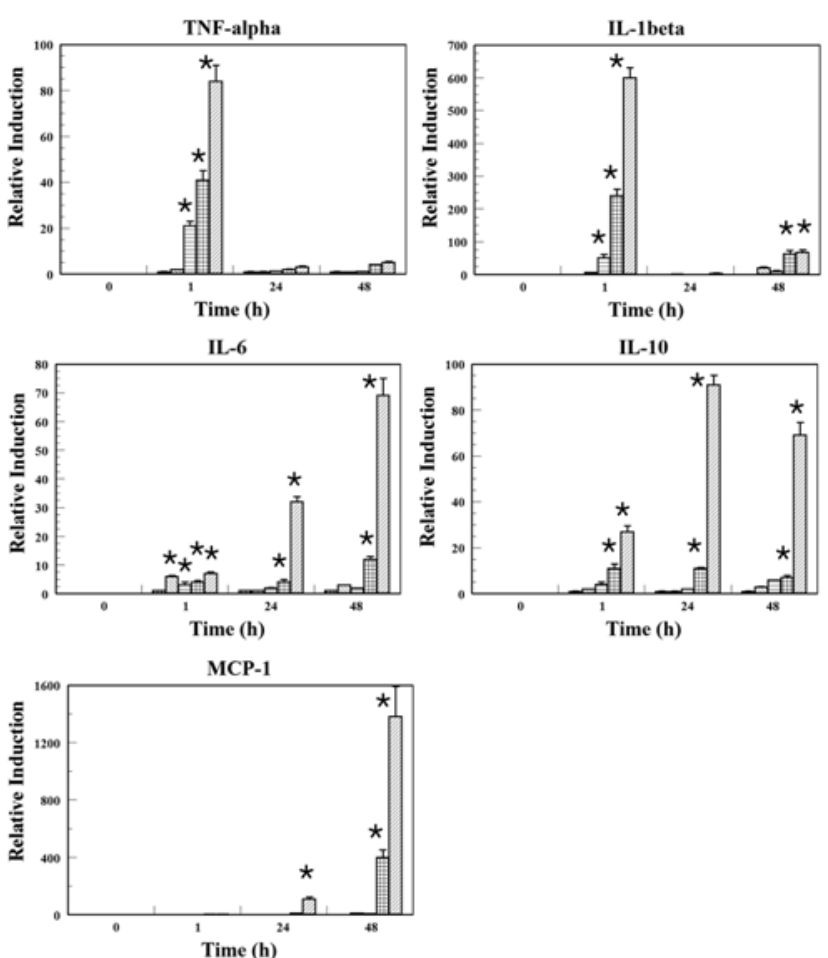

Fig. 5. Cytokine expression using realtime PCR. Effect of Kangai Fuzheng Powder $(0,1,10,100 \& 1000 \mu \mathrm{g} / \mathrm{ml})$ on induction of cytokines in Raw264.7 macrophage cells was evaluated using real-time PCR analysis at $1,24, \& 48 \mathrm{~h}$ after drug treatment. Gene expression of TNF-alpha, $I L-1$ beta, $\|-6\| L-$,10 \& MCP-1 was markedly enhanced by drug treatment in a dose dependent manner. Statistically significant at $\mathrm{P}<0.05$ of values ${ }^{*}$ compared with the time point at 0 .

\section{Phagocytic activity of macrophage}

In addition to cytokine induction, phagocytotic activity of foreign substances was measured to evaluate activation of macrophages. Kangai Fuzheng Powder treatment enhanced the phagocytic activity of macrophages when FITC labeled bacterial debris was incubated for $2 \mathrm{~h}$ 
with macrophages. Normal resting macrophages had a lower level of phagocytic activity but it was potentiated by Kangai Fuzheng Powder treatment in a dose dependent manner (Fig. 6).

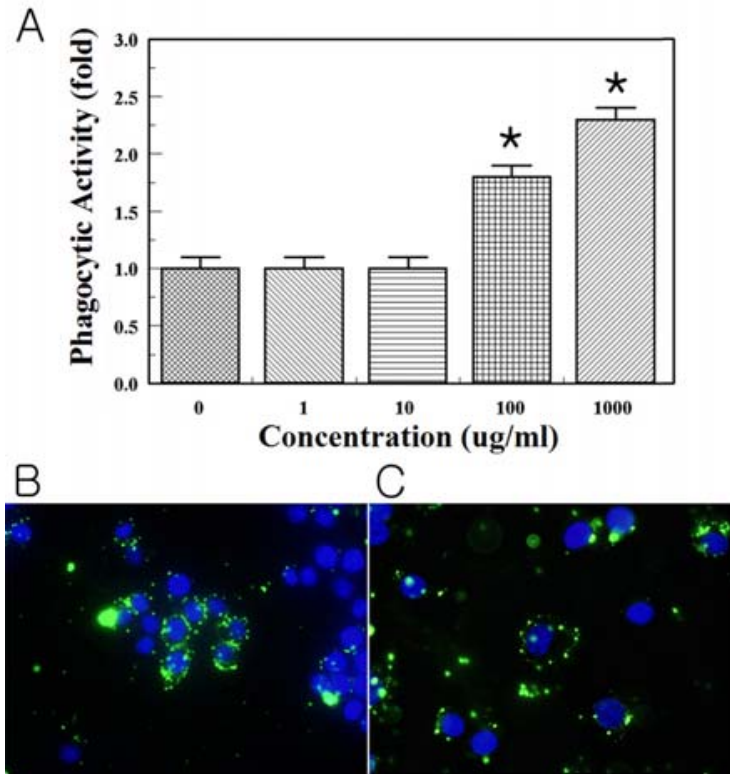

Fig. 6. Phagocytosis assay. Effect of Kangai Fuzheng Powder (0, $1,10,100 \& 1000 \mu \mathrm{g} / \mathrm{ml}$ ) on phagocytic function of Raw264.7 macrophage cells was observed. Phagocytosis was increase in a dose dependent manner. Statistically significant at $P<0.05$ of values * compared with the concentration at $0(A)$. Representative images of phagocytosis were obtained in LPS $(1 \mu \mathrm{g} / \mathrm{ml})$ treated macrophages as a positive control (B) and macrophages treated with Kangai Fuzheng Powder $(1000 \mu \mathrm{g} / \mathrm{ml})$ for $48 \mathrm{~h}(\mathrm{C})$.

\section{Discussions}

Treatment of Kangai Fuzheng Powder was not toxic to cancer cells when applied directly but was toxic when macrophages were co-cultured with cancer cells. This result suggests that anti-cancer effect of Kangai Fuzheng Powder might be mediated by some indirect mechanisms. Macrophages and microglia showed direct toxicity by Kangai Fuzheng Powder while other cells showed no toxic response. We speculate the susceptibility of immune cells to Kangai Fuzheng Powder is related to immune reaction caused by cell themselves. Once immune cells are exposed to Kangai Fuzheng Powder, the cells undergo activation process and then cause apoptosis to terminate its action spontaneously as it is shown in most inflammation or immune cases. Indirect toxicity observed in cancer cells co-cultured with macrophages supported our speculation that Kangai Fuzheng Powder activates macrophages. We hypothesize that some biologically active materials, such as cytokines, are secreted from the macrophages and cause injury to cancer cells. After treatment of Kangai Fuzheng Powder, there was a dramatic morphological change of macrophages from small round resting to bigger activated macrophages. When macrophages were activated, the number of live cells observed under the same magnigication of microscope was less than resting cells. There were some dead cells observed as well. This change provides direct evidence that Kangai Fuzheng Powder can trigger macrophage activation. Activation of macrophages was confirmed by measuring the cytokine induction and phagocytic activity. During the acute period, induction of TNF-alpha and IL-1beta was marked and IL-6, IL-10 and MCP-1 were prominently at delayed period. Phagocytosis of bacterial debris was also enhanced by Kangai Fuzheng Powder treatment. Both cytokine induction and phagocytosis was dose dependently increased.

\section{Conclusions}

In order to investigate the effects of Kangai Fuzheng Powder on cancer cells and macrophages using in vitro culture system, we had conclusion as follows.

1. Kangai Fuzheng Powder had no toxic effects on cells, with a wide safety margin, since it only has toxic effects on cells at dosages over 100 times more concentrated than anti-cancer dosages.

2. Kangai Fuzheng Powder's mechanism of anti-cancer action is through the activation of the phagocytic activity of macrophages

3. Kangai Fuzheng Powder also induced cytokines,

We conclude that Kangai Fuzheng Powder can be used as a new approach to develop anti-cancer with lesser side effects and can be used as immune promoting drug as well.

\section{References}

1. Zhao H, Li Y, Wang Y, Zhang J, Ouyang X, Peng $\mathrm{R}$, Yang J. Antitumor and immunostimulatory activity of a polysaccharide-protein complex from Scolopendra subspinipes mutilans L.Koch in tumor-bearing mice. Food Chem Toxicol. 2012 ; 50 : 2648-55.

2. Varker KA, Ansel A, Aukerman G, Carson WE 3rd. Review of complementary and alternative medicine and selected nutraceuticals: background for a pilot study on nutrigenomic intervention in patients with advanced cancer. Altern Ther Health Med. 2012 ; $18: 26-34$. 
3. Cao ZY, Chen XZ, Liao LM, Peng J, Hu HX, Liu ZZ, Du J. Fuzheng Yiliu Granule inhibits the growth of hepatocellular cancer by regulating immune function and inducing apoptosis in vivo and in vitro. Chin J Integr Med. 2011 ; 17 : 691-7.

4. Lin YL, Lai WL, Harn HJ, Hung PH, Hsieh MC, Chang KF, Huang XF, Liao KW, Lee MS, Tsai NM. The Methanol Extract of Angelica sinensis Induces Cell Apoptosis and Suppresses Tumor Growth in Human Malignant Brain Tumors. Evid Based Complement Alternat Med. 2013 ; 2013 : 394636-44.

5. Jiang Z, Jiang J, Wang Q, Zhang L, Wu C, Yang H. A Study on Screening of Osteosarcoma U2OS Cell Inhibiting Active Components from Nidus Vespae. Afr J Tradit Complement Altern Med. 2013 ; $10: 464-8$.

6. Xu XF, Zhang TL, Jin S, Rong W, Xiao X, Zhang WD, Wang PY, Wang XJ. Ardipusilloside I induces apoptosis by regulating $\mathrm{Bcl}-2$ family proteins in human mucoepidermoid carcinoma Mc3 cells. BMC Complement Altern Med. 2013 ; 21 : 322-30.

7. Wang $\mathrm{H}, \mathrm{Fu} \mathrm{Z}$, Han C. The Medicinal Values of Culinary-Medicinal Royal Sun Mushroom (Agaricus blazei Murrill). Evid Based Complement Alternat Med. 2013 ; 2013 : 842619-24.

8. Yanju B, Yang L, Hua B, Hou W, Shi Z, Li W, Li C, Chen C, Liu R, Qin Y, Lv W. A systematic review and meta-analysis on the use of traditional Chinese medicine compound kushen injection for bone cancer pain. Support Care Cancer. 2013 ; DOI 10.1007/s00520-013-2063-5.

9. Ruan SM, Shen MH, Lin H, Zheng LP, Wang Y, Li MT. Jiedu sangen decoction intervened carcinoma-associated fibroblasts and inhibited migration and invasion of colon cancer: an experimental research. Zhongguo Zhong Xi Yi Jie He Za Zhi. 2013 ; 33 : 1242-6.

10. Kpoviessi S, Bero J, Agbani P, Gbaguidi F, Kpadonou-Kpoviessi B, Sinsin B, Accrombessi G, Frederich M, Moudachirou M, Quetin-Leclercq J. Chemical composition, cytotoxicity and in vitro antitrypanosomal and antiplasmodial activity of the essential oils of four Cymbopogon species from Benin. J Ethnopharmacol. 2013 ; DOI 10.1016/j.jep.2013.11.027.

11. Mao Q, Zhang PH, Wang Q, Li SL. Ginsenoside F2 induces apoptosis in humor gastric carcinoma cells through reactive oxygen species-mitochondria pathway and modulation of ASK-1/JNK signaling cascade in vitro and in vivo. Phytomedicine. 2013 ; DOI 10.1016/j.phymed.2013.10.013.
12. Jiang X, Huang XC, Ao L, Liu WB, Han F, Cao J, Zhang DY, Huang CS, Liu JY. Total alkaloids of Tripterygium hypoglaucum (levl.) Hutch inhibits tumor growth both in vitro and in vivo. Ethnopharmacol. 2013 ; DOI 10.1016/j.jep.2013.10.045.

13. Kim A, Im M, Yim NH, Jung YP, Ma JY. Aqueous Extract of Bambusae Caulis in Taeniam Inhibits PMA-Induced Tumor Cell Invasion and Pulmonary Metastasis: Suppression of $\mathrm{NF}-\kappa \mathrm{B}$ Activation through ROS Signaling. PLoS One. 2013 ; DOI 10.1371/journal.pone.0078061.

14. Yang W. Kangai Fuzheng powder for the treatment of malignant tumor. Fourth Conference of the World Traditional Medicine. 1998.

15. Lee S, Park JY, Lee WH, Kim H, Park HC, Mori K, Suk K. Lipocalin-2 is an autocrine mediator of reactive astrocytosis. J Neurosci. 2009 ; 29 : $234-49$. 